\title{
Blue carotenoids
}

\section{Synnøve Liaaen-Jensen* and Geir Kildahl-Andersen}

Department of Chemistry, Norwegian University of Science and Technology (NTNU), Trondheim, NO-7491, Norway

E-mail: slje@chem.ntnu.no

This paper is dedicated to an old friend and colleague, Professor Torbjörn Norin, who has contributed also to the chemistry of isoprenoid compounds

\begin{abstract}
A review on the chemistry of blue carotenoids, emphasizing own contributions, is presented. Treated are violerythrin, carotenoid oxonium ions, preparation and characterization of carotenoid cations ( $<\mathrm{C}_{40}, \mathrm{C}_{40},>\mathrm{C}_{40}$-skeletal analogs), the Carr-Price Vitamin A blue colour reaction, carotenoid-iodine complexes and blue carotenoproteins.
\end{abstract}

Keywords: Polyenyl cations, preparation, characterization, retinoids, carotenoproteins

\section{Contents}

1. Introduction

2. Violerythrin

3. Oxonium ions

4. Carotenoid Carbocations

4.1 Preparation and characterization

$4.2 \mathrm{C}_{40}$-carotenoid cations

4.3 Cations of carotene analogs with extended polyene chain

4.4 Shorter polyenylic dications

5. The Carr-Price Vitamin A Blue Colour Reaction

6. Carotenoid Iodine Complexes

7. Blue Carotenoproteins

8. Conclusions

References 


\section{Introduction}

Amongst the isoprenoids the carotenoids constitute a class of coloured polyenes, mainly with $\mathrm{C}_{40^{-}}$ skeletons, as illustrated by $\beta, \beta$-carotene (1). ${ }^{1}$ Whereas a few colourless representatives are known, the majority are yellow-orange-red pigments widely distributed in Nature. ${ }^{2}$ No blue carotenoids are naturally occurring in an uncomplexed state. However, various carotenoids may be derivatized to blue products, and the chemistry of these reactions has been revealed mainly within the last two decades. The blue products comprise conjugated cyclopentenediones, oxonium ions, carbocations, iodine complexes and carotenoproteins. Their chemistry is briefly reviewed in this account, emphasizing own contributions.

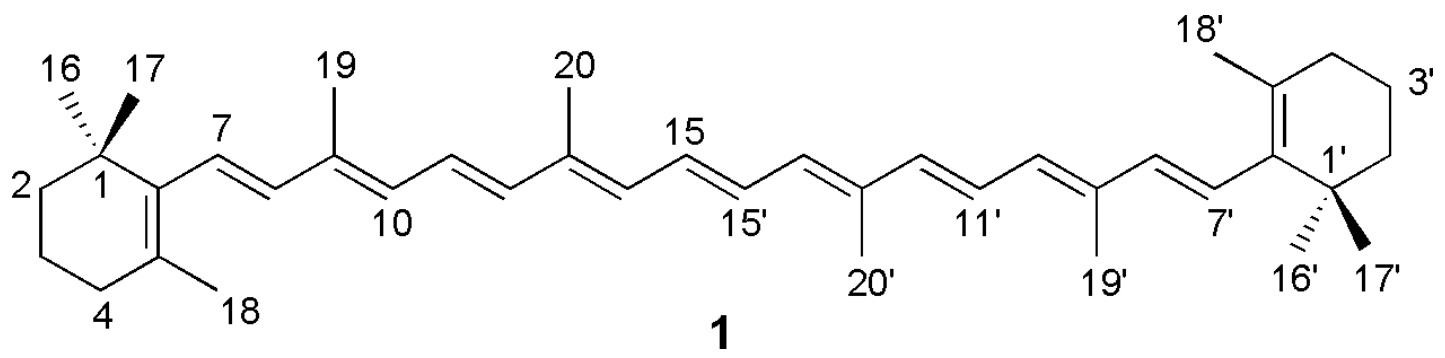

\section{Violerythrin}

Astaxanthin (2), the typical red carotenoid of salmon and boiled lobster, ${ }^{2}$ is known to undergo facile oxidation in the presence of bases and oxygen to the enolized diketone astacene (3) with closely similar absorption maximum. ${ }^{3}$ The $\mathrm{C}_{38}$ skeletal 2,2'-dinor carotenoid diester actinioerythrin (4) from sea anemones reacts in a similar way to provide the blue cyclopentenedione violerythrin (5, $\lambda_{\max } 549 \mathrm{~nm}$ in acetone), unable to enolize, Scheme $1 .{ }^{4,5}$

Violerythrin (5) was later prepared by total synthesis. ${ }^{6}$ As a curiosity it may be mentioned that the industrial application of the blue product $\mathbf{5}$ as an eye cosmetics was once considered. 
<smiles>C=C1C(C)=C(/C=C/C(C)=C/C=C/C(C)=C/C=C/C=C(C)/C=C/C=C(C)/C=C/C2=C(C)C(=O)[C@@H](O)CC2(C)C)C(C)(C)C[C@H]1O</smiles><smiles>CC1=C(/C=C/C(C)=C/C=C/C(C)=C/C=C/C=C(C)/C=C/C=C(C)/C=C/C2=C(C)C(=O)C(O[IH])=CC2(C)C)C(C)(C)C=C(O[IH])C1=O</smiles><smiles>[R]C(=O)O[C@@H]1C(=O)C(C)=C(/C=C/C(C)=C/C=C/C(C)=C/C=C/C=C(C)/C=C/C=C(C)/C=C\C2=C(C)C(=O)[C@H](OC([R])=O)C2(C)C)C1(C)C</smiles>

\section{Scheme 1}

\section{Oxonium Ions}

Since Karrer's work in the forties it has been known that carotenoid 5,6-epoxides undergo epoxidefuranoxide rearrangement with weak Brønsted acid and subsequently transferred to blue products by treatment with concentrated acid. ${ }^{7,8}$ The chemistry of the blue colour reaction was revealed in the early nineties. ${ }^{9,10}$ Examples are given below for carotenoid mono- and diepoxides. Fucoxanthin (6), with the 5,6-epoxy group close to the carbonyl function, is converted by $\mathrm{HCl}$ via the hemiketal 7 to 
the blue oxonium ion $\mathbf{8}$, which is readily transformed to the yellow hemiketal $\mathbf{7}$ with base, Scheme $2^{9}$<smiles>CC(=O)O[C@H]1C[C@@H](C)C(=C=C=C(C)C=CC=C(C)C=CC=CC=C(C)C=CC=C(C)C(=O)C[C@]2(O)C(C)(C)C[C@@H](O)C[C@]2(C)O)C(C)(C)C1</smiles><smiles>CC=C(C)C(=O)C[C@]1(O)C(C)(C)C[C@@H](O)CC1(C)C</smiles>

6

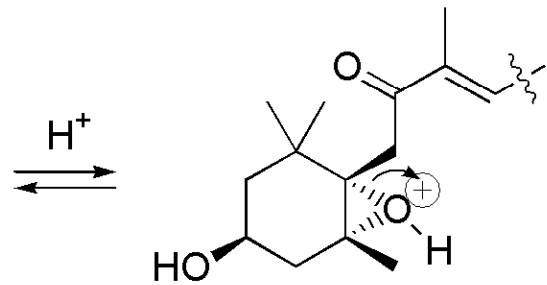

$\longrightarrow$

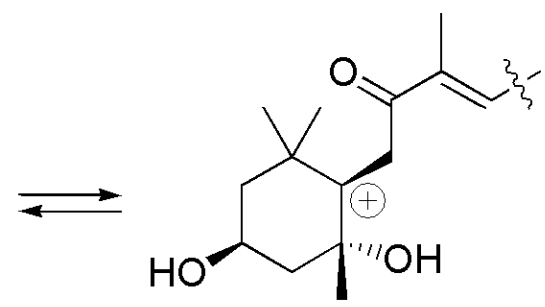

$\uparrow \mathrm{C}-6,7$ rotation

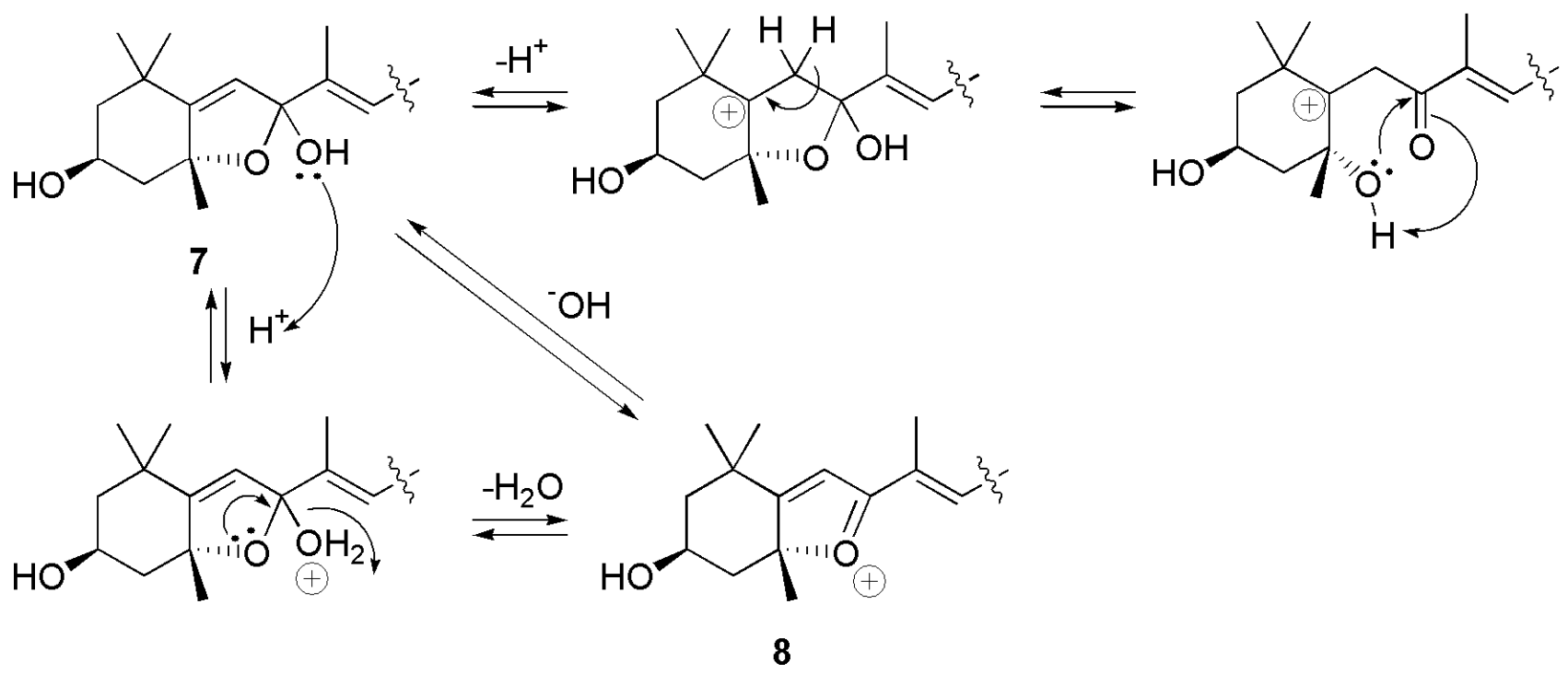

\section{Scheme 2}

The colour changes occurring during the final steps in this reaction scheme is illustrated in Figure 1. The orange fucoxanthin (6) is converted to the yellow hemiketal (7) by weak acid and by stronger acid to the blue oxonium ion (8). Like an indicator in an acid-base reaction is the blue oxonium ion (8) reconverted to the stable yellow hemiketal (7) with base. Back reaction to the blue oxonium ion occurs spontaneously with strong acid. ${ }^{9}$ 


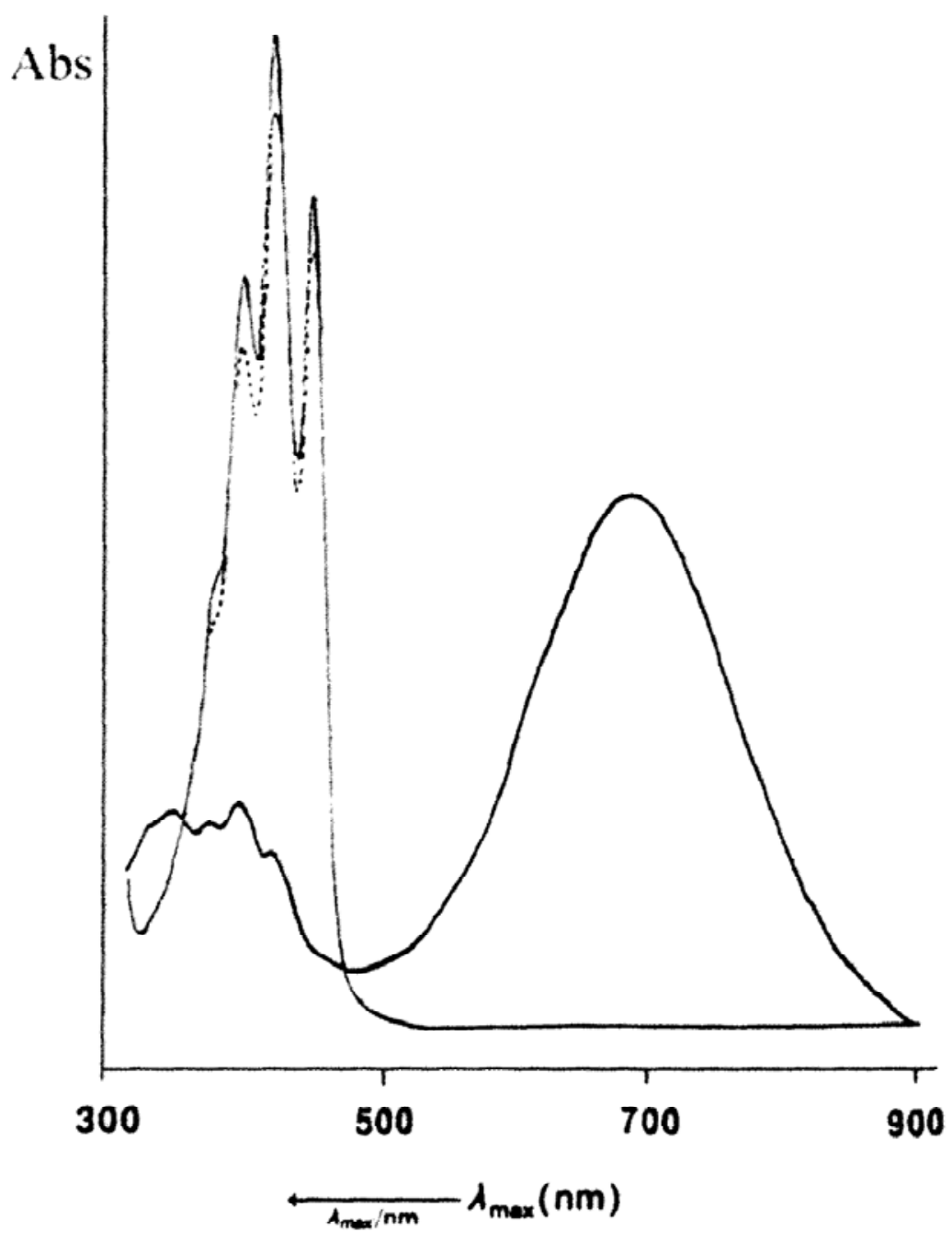

Figure 1. Absorption spectra of fucoxanthin hemiketal (7, solid line), the blue oxonium ion produced by treatment with acid $\left(\mathbf{8}, \lambda_{\max } 690 \mathrm{~nm}\right)$, fucoxanthinol hemiketal formed by subsequent treatment with base (dotted line). ${ }^{9}$

The simpler 5,6-epoxide neoxanthin (9) is converted to the furanoxide by weak acid and by concentrated trifluoroacetic acid to the blue oxonium ion $\mathbf{1 0}$, Scheme 3 , which again may be reacted with base to the stable yellow hemiketal 11, Scheme $3 .{ }^{10}$ During these transformations the allenic end group in neoxanthin (9) was converted to the acetylenic end group in product $\mathbf{1 1 .}$ 


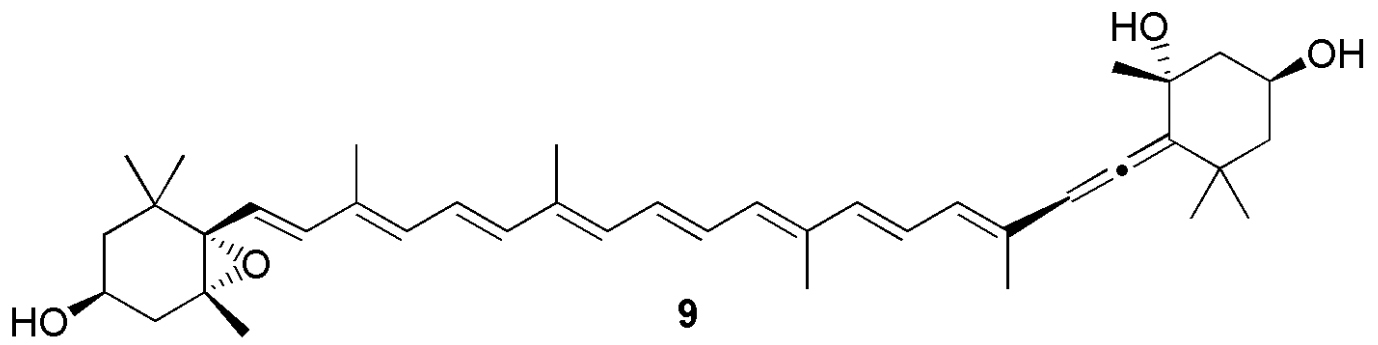<smiles>C=C[C@H](C)/C=C(C)/C=C/[C@]12O[C@@]1(C)C[C@@H](O)CC2(C)C</smiles>

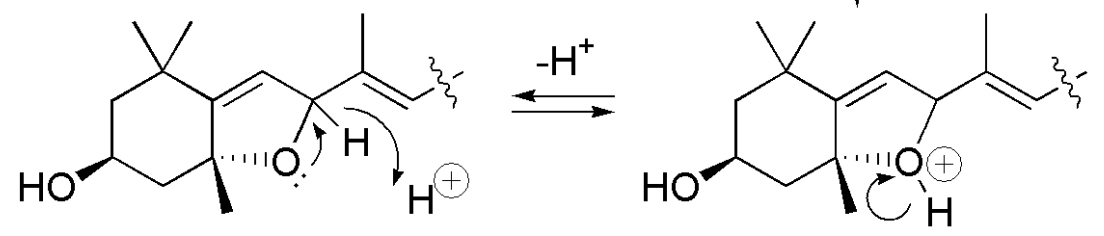
$\mathrm{CF}_{3} \mathrm{COOH} \downarrow-\mathrm{H}_{2}$<smiles>CC(C#CC1=C(C)CC(C)CC1(C)C)=C/C=C/C(C)=C/C=C/C=C(C)/C=C/C=C(\C)C1=[O+][C@@]2(C)C[C@H](O)CC(C)(C)C2=C1</smiles>
$\mathrm{KOH}, \mathrm{MeOH} \mid \downarrow \begin{aligned} & \text { dilute } \mathrm{HCl} \\ & \mathrm{MeOH}\end{aligned}$<smiles>C=C(C#C/C(C)=C/C=C/C(C)=C/C=C/C=C(C)/C=C/C=C(\C)C1(O)C=C2C(C)(C)C[C@@H](O)C[C@]2(C)O1)C(C)(C)CC</smiles>

\section{Scheme 3}

The diepoxide violaxanthin (12) was in similar manner transformed to the blue mono- (13) and dioxonium ions (14), Scheme 4, which could be converted to the respective, stable mono- and dihemiketals. $^{10}$ 


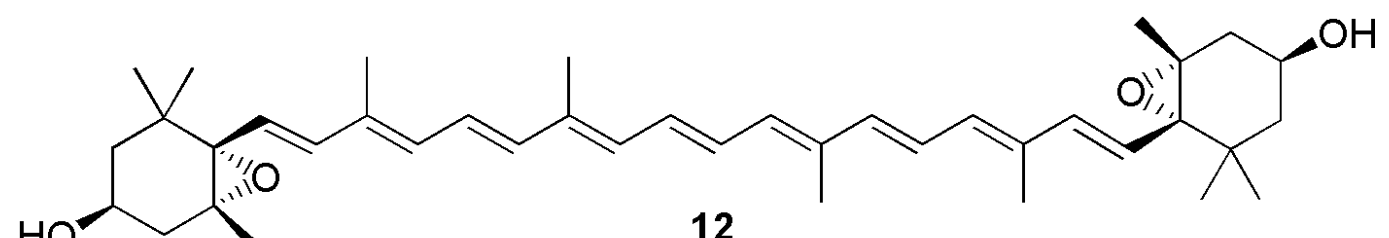

12

conc. $\mathrm{HCl}$

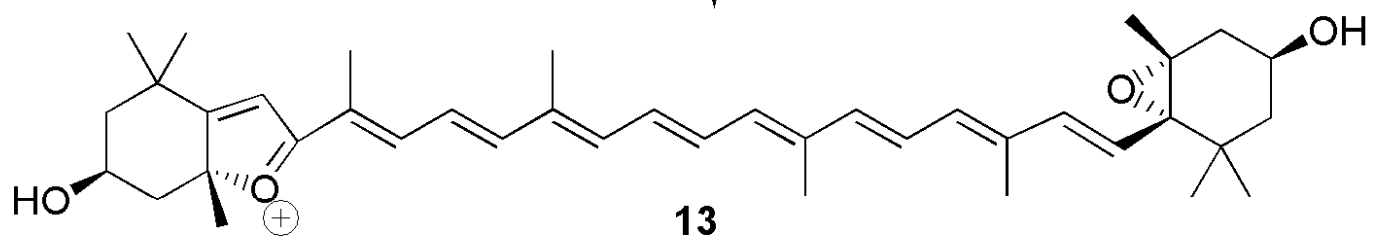<smiles>CC1=CC(=O)[C@@]2(C)C=C(C(=O)/C(C)=C/C=C/C(C)=C/C=C/C(C)=C/C=C/1)C(C)(C)C[C@@H](O)C2</smiles>
$\mathrm{KOH}, \mathrm{MeOH} \downarrow \mid \begin{aligned} & \text { dilute } \mathrm{HCl} \\ & \mathrm{MeOH}\end{aligned}$

dihemiketal

\section{Scheme 4}

The identification of the oxonium ions studied above was mainly based on their VIS/NIR absorption and conversion to characterized hemiketals. Detailed NMR spectra could not be achieved, albeit downfield shift of olefinic protons is consistent with the positive charge. Less extensive charge delocalization than for the carotenoid cations treated later, and preference for the oxonium ion structure, are assumed.

\section{Carotenoid Carbocations}

\subsection{Preparation and characterization}

Convenient methods for the preparation of carotenoid carbocations are: ${ }^{11,12}$

(a) From carotenes with the Lewis acid $\mathrm{BF}_{3}$-etherate as reagent, where $\mathrm{BF}_{3}$ serves as a strong electrophile, removing electrons from the polyene chain.

(b) From allylic carotenols with $\mathrm{CF}_{3} \mathrm{COOH}$ or $\mathrm{CF}_{3} \mathrm{SO}_{3} \mathrm{H}$ in $\mathrm{CH}_{2} \mathrm{Cl}_{2}$ for selective protonation of hydroxy groups, rather than protonation of the polyene chain. The protonated hydroxy group is a good leaving group. 
The carbocations are formed in quantitative yield and exhibit considerable stability at room temperature due to charge delocalization.

The blue colour is caused by absorption in the VIS-NIR region $\left(\lambda_{\max }\right.$ around $900 \mathrm{~nm}$ ) and the stability is monitored by NIR measurements. Carotenoid radical cations exhibit closely similar NIR spectra in comparison with the diamagnetic cation, but may be distinguished by EPR spectra and lower stability.

NMR spectroscopy has been successfully adapted for detailed structural analyses of diamagnetic carotenoid carbocations. High field 2D NMR spectra, including ${ }^{1} \mathrm{H}-{ }^{1} \mathrm{H}$ COSY, ROESY, ${ }^{1} \mathrm{H}-{ }^{13} \mathrm{C}$ HSQC and ${ }^{1} \mathrm{H}_{-}{ }^{13} \mathrm{C}$ HMBC, recorded at $-10{ }^{\circ} \mathrm{C}--20{ }^{\circ} \mathrm{C}$, provide the following key information:

(i) total downfield shifts for all carbon atoms is ca. $250 \mathrm{ppm}$ for monocations and $500 \mathrm{ppm}$ for dications.

(ii) the charge distribution may be estimated by comparison of the ${ }^{13} \mathrm{C}$ shift of individual carbons relative to a relevant, neutral model. Relative charge is conveniently illustrated by the size of filled circles, vide infra.

(iii) bond order (single, intermediate, double) may be estimated from ${ }^{1} \mathrm{H}-{ }^{1} \mathrm{H}$ coupling constants in comparison with known coupling constants across single and double bonds in appropriate models. Intermediate bonds are illustrated by dotted bonds.

Quenching reactions provide additional information. Carotenoid cations react with various O-, $\mathrm{N}$ - and S-nucleophiles to neutral products that may be isolated and identified (VIS, MS, ${ }^{1} \mathrm{H} \mathrm{NMR}$ ), the structure of which may support the structure assigned to the parent carbocation by NIR and NMR spectroscopy. ${ }^{13-15}$

\section{2 $\mathrm{C}_{40}$-carotenoid cations}

Several mono- and dications have been prepared and characterized. Representative examples are given. $\beta$, $\beta$-Carotene dication (15) was prepared from $\beta$, $\beta$-carotene (1) reacted with $\mathrm{BF}_{3}$-dimethyl etherate. Radical species were shown to be present by EPR, supporting a reaction mechanism with two successive one-electron oxidations via the radical cation. This blue cation $\left(\lambda_{\max } 985 \mathrm{~nm}\right.$ in the NIR region) had considerable stability. The estimated charge distribution, compatible with charge repulsion, bond reversal and regions of intermediate bonds should be noted, as well as the conformation of the C-6,7 (C-6',7’) single bonds. ${ }^{13}$

The dication 16a-c, prepared by allylic elimination of $\beta$, $\beta$-carotene-4,4'-diol, occurred as three stereoisomers according to NMR data. Estimated charge distribution for the all-E-isocarotene dication (16c) shows similar structural features as the dication $\mathbf{1 5}^{16}$ 


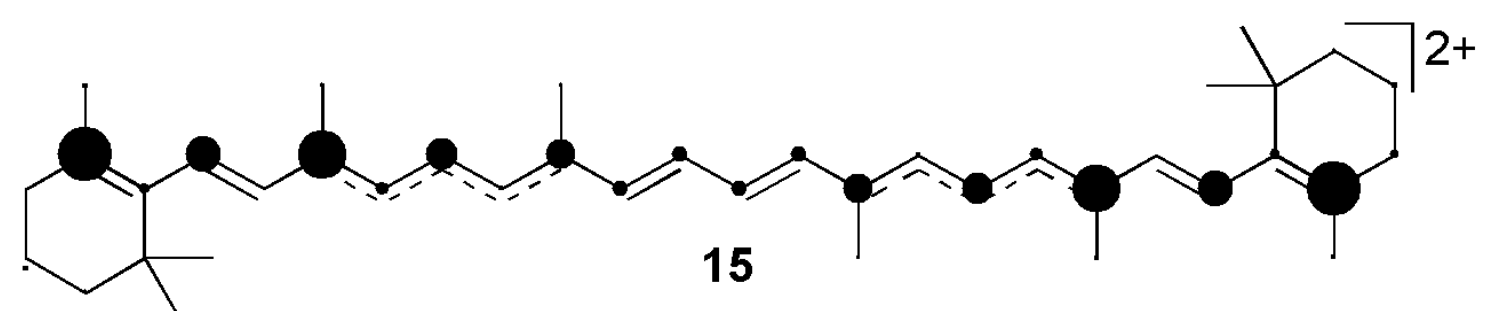<smiles>CC(=C=C=C1C(C)=CCCC1(C)C)C=CC=C(C)C=CC=C(C)C=CC=C(C)C=C=C1C(C)=CCCC1(C)C</smiles><smiles>CC(=C=C=C1C(C)=CCCC1(C)C)C=CC(C)=CC=CC=C(C)C=CC=C(C)C=C=C1C(C)=CCCC1(C)C</smiles><smiles></smiles>

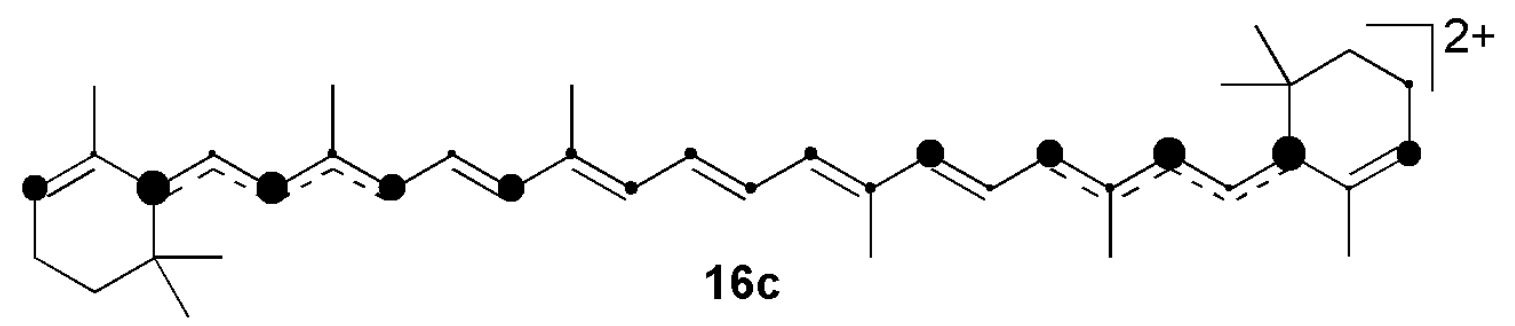

The monocations 17a-d, prepared by allylic elimination of $\beta, \beta$-caroten-4-ol, consisted of four stereoisomers with end group modifications. The charge distribution for $\mathbf{1 7 a} \mathbf{a} \mathbf{b}$ differ from that of the dications with central location in a region of intermediate bonds. ${ }^{16,17}$ 
<smiles>CC(=C=C=CC(C)=CC=C1C(C)=CCCC1(C)C)C=C=C=CC(C)=C=CC=C(C)C=CC1=C(C)CCCC1(C)C</smiles>

$17 \mathbf{a},(6 E, 6 \text { 6'-s-cis })^{\prime}$<smiles>CC(=C=C=CC(C)=CC=C1C(C)=CCCC1(C)C)C=C=C=CC(C)=C=CC=C(C)C=CC1=C(C)CCCC1(C)C</smiles>

$17 \mathrm{~b},(6 Z, 6 \text { '-s-cis })^{-}$<smiles>CC1=CCCC(C)(C)C1=C/C=C(C)/C=C/C=C(\C)C=C=C=C/C(C)=C/C=C(C)/C=C/C1=C(C)CCCC1(C)C</smiles>

$17 \mathrm{c},(6 E, 6$ '-s-trans)<smiles>CC(=C=C=CC(C)=CC=C1C(C)=CCCC1(C)C)C=C=C=CC(C)=CC=CC(C)=CC=CC1=C(C)CCCC1(C)C</smiles>

$17 d,(6 Z, 6$ '-s-trans)

\subsection{Cations of carotene analogs with extended polyene chain}

The 4-dehydro- $\beta$, $\beta$-carotenyl monocation (17) is the longest delocalized cation fully characterized by NMR spectroscopy, including charge distribution. By regression analysis a soliton half width of $l$ = 7.8 was calculated. A soliton is described in the SSH (Su-Schrieffer-Heeger) theory by a charge density wave, with a width defined by the soliton half-width $l$.

Polyenyl cations with longer polyene systems were prepared from $\mathrm{C}_{50^{-}}, \mathrm{C}_{54^{-}}$and $\mathrm{C}_{60^{-}}$-carotene analogs, aiming at determining the maximum soliton half width. However, detailed charge distribution data could not be obtained, compatible with the mobility of the free solition and NMR signal averaging in dynamic systems. ${ }^{14}$ The absorption maxima plotted against the number of $s p^{2}$ hybridised carbons of shorter polyenyl cations, ${ }^{18}$ together with the maxima recorded for the $\mathrm{C}_{40}$ monocation, Part 4.2, and the longer polyenyl cations are shown in Figure 2. 


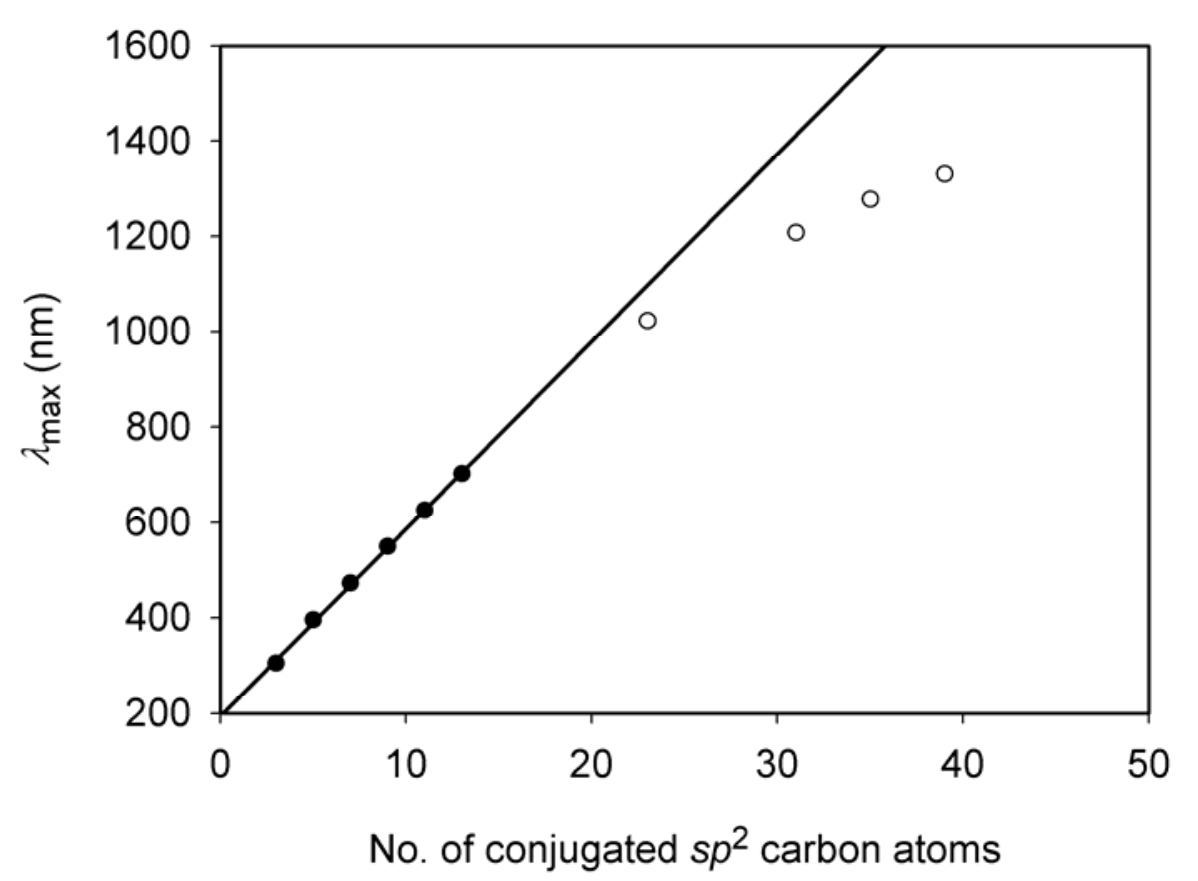

Figure 2. Absorption maxima at room temperature as function of the number of conjugated $s p^{2}$ hybridised carbon atoms in polyenyl monocations. - From ref. ${ }^{18}$, in $80-96 \%$ sulfuric acid. $\bigcirc$ Polyenes 1, 14-16, dissolved in $0.013 \mathrm{M}$ trifluoroacetic acid in $\mathrm{CH}_{2} \mathrm{Cl}_{2}$.

Deviations from the linearity of the free electron model ${ }^{18,19}$ is seen already for the monocation 17 with $23 s p^{2}$ carbon atoms. This may be taken as evidence for the manifestation of free solitions in these longer polyenes.

\subsection{Shorter polyenylic dications}

Carotenoids absorb light below ca. $550 \mathrm{~nm}$, blue carotenoproteins, vide infra, around ca. $600 \mathrm{~nm}$ and carotenoid cations have $\lambda_{\max }$ above $870 \mathrm{~nm}$. In order to fill the gap in the VIS-NIR absorption of carotenoid related compound in the 700-900 $\mathrm{nm}$ region, shorter polyenylic dications were synthesized, $18\left(\mathrm{C}_{10^{-}}\right), 19\left(\mathrm{C}_{20^{-}}\right)$and $20\left(\mathrm{C}_{24^{-}}\right)$and charactherized by $\lambda_{\max } 438,735$ and $850 \mathrm{~nm}$, respectively. ${ }^{20}$ 


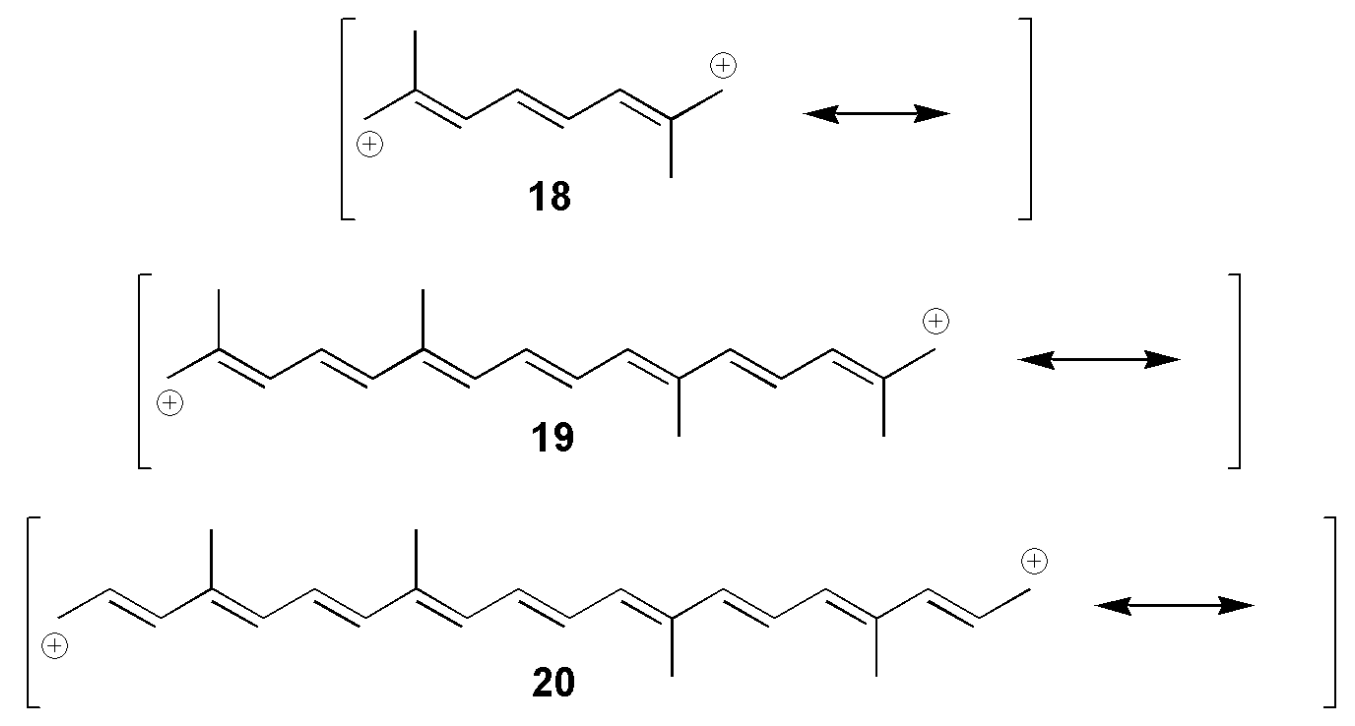

An empirical correlation for $\lambda_{\max }$ and polyene length was developed, where $m$ is the number of $s p^{2}$ hybridized carbon atoms. ${ }^{20}$

Monocations: $\lambda_{\max }=(204.8+38.3 m) \mathrm{nm}$

Dications: $\lambda_{\max }=(156.0+35.4 \mathrm{~m}) \mathrm{nm}$

The wide spectral UV-VIS-NIR absorption covered by carotenoids is illustrated in Figure 3.

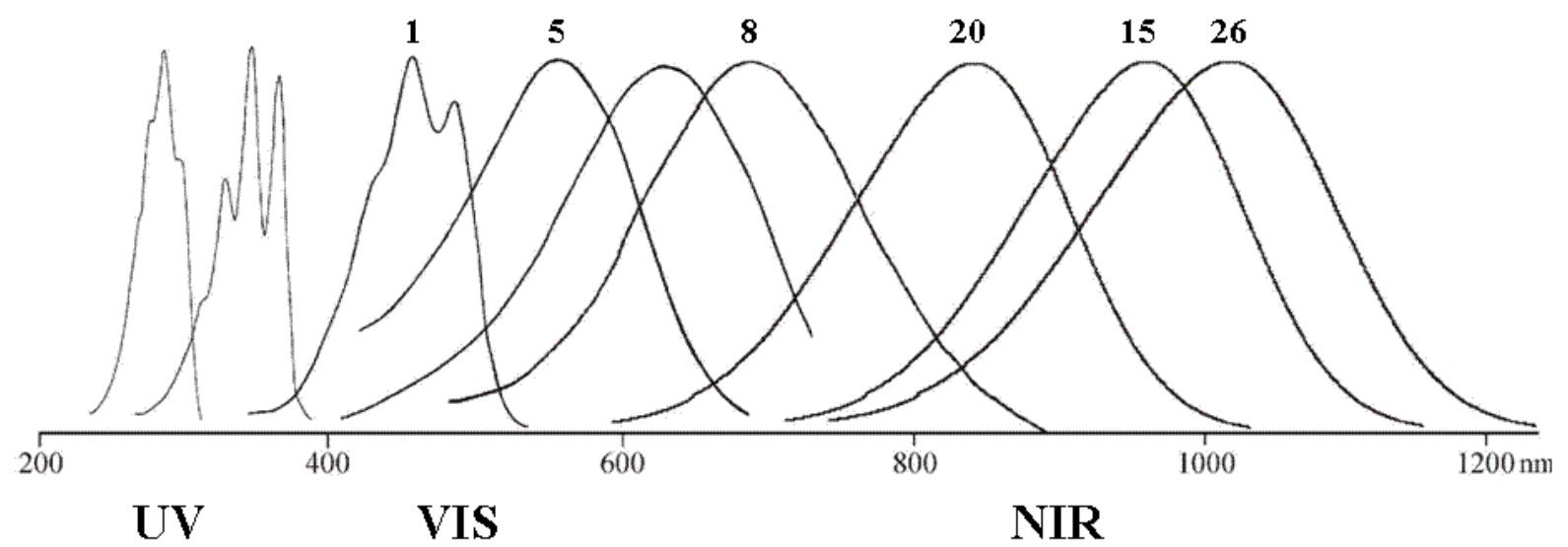

Figure 3. UV/VIS/NIR absorption spectra of selected carotenoids, from left the colorless phytoene (conjugated triene) and phytofluene (conjugated pentaene), $\beta, \beta$-carotene (1), violerythrin (5), crustacyanin (carotenoprotein), fucoxanthin oxonium ion (8), $\mathrm{C}_{24}$-dication (20), $\beta, \beta$-carotene dication (15), and $\beta, \beta$-carotene-iodine solvent complex (26). 


\section{The Carr-Price Vitamin A Blue Colour Reaction}

The classical Carr-Price blue colour reaction for the quantitative determination of Vitamin A content has recently been reinvestigated. ${ }^{21-24}$ When Vitamin A (retinol, 21) is reacted with $\mathrm{SbCl}_{3}$ (a Lewis acid) in $\mathrm{CHCl}_{3}$, an unstable blue colour is developed, which may be quantified spectrometrically $\left(\lambda_{\max } 620 \mathrm{~nm}\right)$. A more stable product with closely similar $\lambda_{\max }(622 \mathrm{~nm})$ is obtained upon treatment with Brønsted acid.

It is now confirmed by NMR data that the product obtained with the protic acid $\mathrm{CF}_{3} \mathrm{SO}_{3} \mathrm{H}$ is the anhydroretinyl cation 22 and not the retinyl cation 23, compatible with a reaction via anhydroretinol (24), ${ }^{25}$ Scheme 5. The anhydroretinylic cation consisted of two stereoisomers 22a and 22b, differing in the conformation of the C-6,7 bond (carotenoid numbering) with rather even charge distribution in the short polyene system.

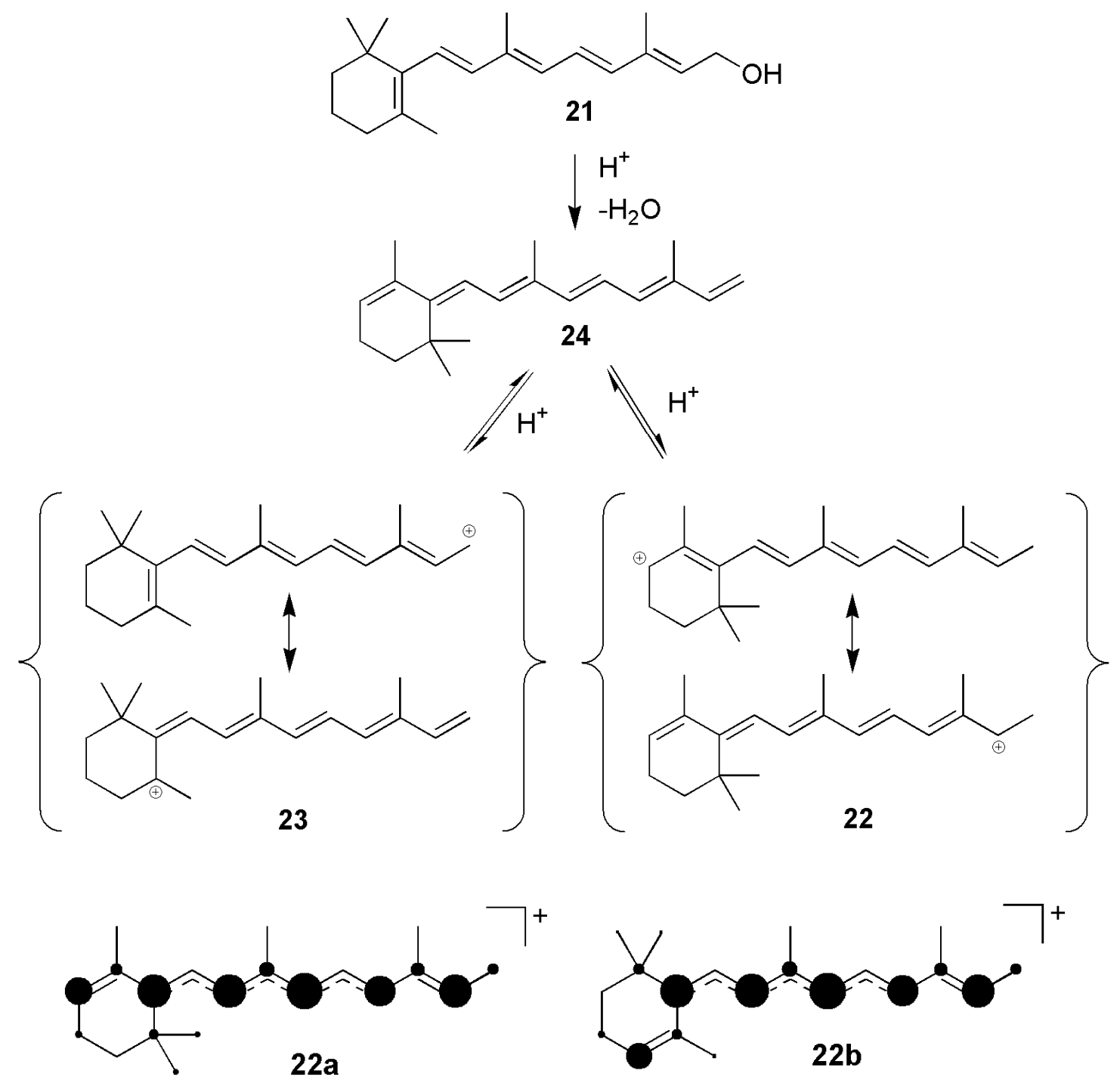

\section{Scheme 5}


Due to the instability and unsuccessful NMR spectra it was suspected that the Carr-Price product might be a radical cation. However, separate studies showed that retinol (21), in contrast to carotenoids, did not readily form radical cations, and it was revealed by light scattering data that strong aggregation could rationalize the results. Addition of sodium methoxide as a nucleophile to the Carr-Price product provided dimeric products, supporting intermolecular retinoid reactions as a major decay pathway for the blue product, rationalizing its observed instability.

Structure 25a is suggested for the monomeric form of the Carr-Price blue product, with a trigonal bipyramidal geometry around the antimony atom, including the stereochemically active lone pair, Scheme 6.<smiles>[Z4]/C=C(C)\C=C\C=C(/C)C=C</smiles><smiles>CC=CC=CC(C)=CC=C1C(C)=CCCC1(C)C</smiles><smiles>CC(=C=C=C1C(C)=CCCC1(C)C)C=CC=C(C)CC[Sb](Cl)(Cl)(Cl)Cl</smiles><smiles>C[Se]CC/C(C)=C/C=C/C(C)=C/C=C1/C(C)=CCCC1(C)C</smiles>

\section{Scheme 6}

\section{Carotenoid Iodine Complexes}

Carotenoid iodine complexes have been studied since 1886, and their history was recently reviewed. ${ }^{26}$ A black solid complex $\left(\mathrm{C}_{40} \mathrm{H}_{56} \mathrm{I}_{4}\right)$ from heptane, as well as a blue solvent complex of $\beta$, $\beta$-carotene (1) with iodine in $\mathrm{CHCl}_{3}\left(\lambda_{\max } 1010 \mathrm{~nm}\right)$ and of $\beta, \beta$-carotene-3,3'-diol have been reexamined by modern methods, inculding UV/VIS/NIR, IR, MS, EPR, ENDOR and NMR $\left({ }^{1} \mathrm{H},{ }^{1} \mathrm{H}-\right.$ ${ }^{1} \mathrm{H}$ COSY, TOCSY, 2D ROESY, ${ }^{1} \mathrm{H}-{ }^{13} \mathrm{C}$ HSQC and ${ }^{1} \mathrm{H}-{ }^{13} \mathrm{C}$ HMBC) spectroscopy and chemical reactions monitored by HPLC, TLC and spectral analysis (VIS, MS, ${ }^{1} \mathrm{H}$ NMR). Iodine is not covalently bound to the carotenoid, and spectroscopic and chemical evidence is rationalized by a $\beta$, $\beta$-carotene-iodine complex with cationic / radical cationic properties, containing iodine in a $\pi$ complex (26), Scheme 7. 

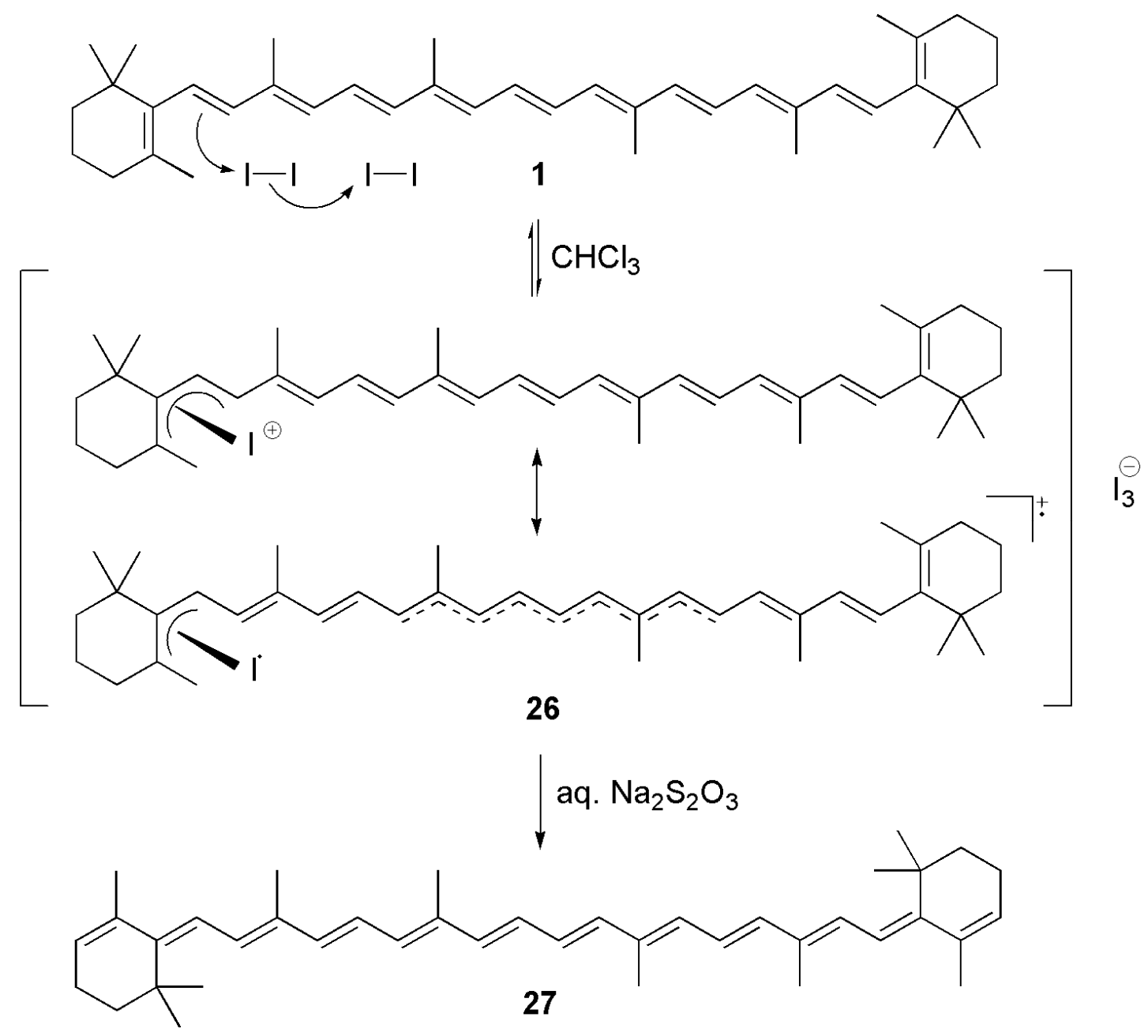

\section{Scheme 7}

The solid complex is considered as the alkane insoluble salt with the same structure $\mathbf{2 6}$ as the solvent complex formed in chlorinated solvents.

The major quenching product of the solvent complex with thiosulfite is isocarotene (27). All quenching products obtained from the iodine complexes are strongly $E / Z$ isomerized, consistent with cationic intermediates.

\section{Blue Carotenoproteins}

Protein-bound carotenoids are responsible for the mauve-blue-black colour of several tissues in invertebrate animals. ${ }^{27}$ The carotenoprotein of the lobster carapace has been extensively studied. ${ }^{27,28}$ Two molecules of astaxanthin (2; all three optical isomers (3R,3'R)-, (3R,3'S, meso)- and (3S,3'S)-2 are involved $)^{29}$ are non-covalently bound to two apoproteins in $\beta$-crustacyanin ( $\lambda_{\max } 587 \mathrm{~nm}$ in phosphate buffer), significatntly bathochromically shifted relative to astaxanthin (2, $\lambda_{\max } 480 \mathrm{~nm}$ in 
acetone). Aggregation of eight $\beta$-crustacyanin units provided $\alpha$-crustacyanin, with further bathochromically shifted $\lambda_{\max }(632 \mathrm{~nm}){ }^{27}$

$\mathrm{X}$-ray studies of $\beta$-crustacyanin have established the structure of the apoproteins and the amino acid residues binding to the astaxanthin (2) molecule, Figure 4. Water molecules are also involved. ${ }^{30,31}$

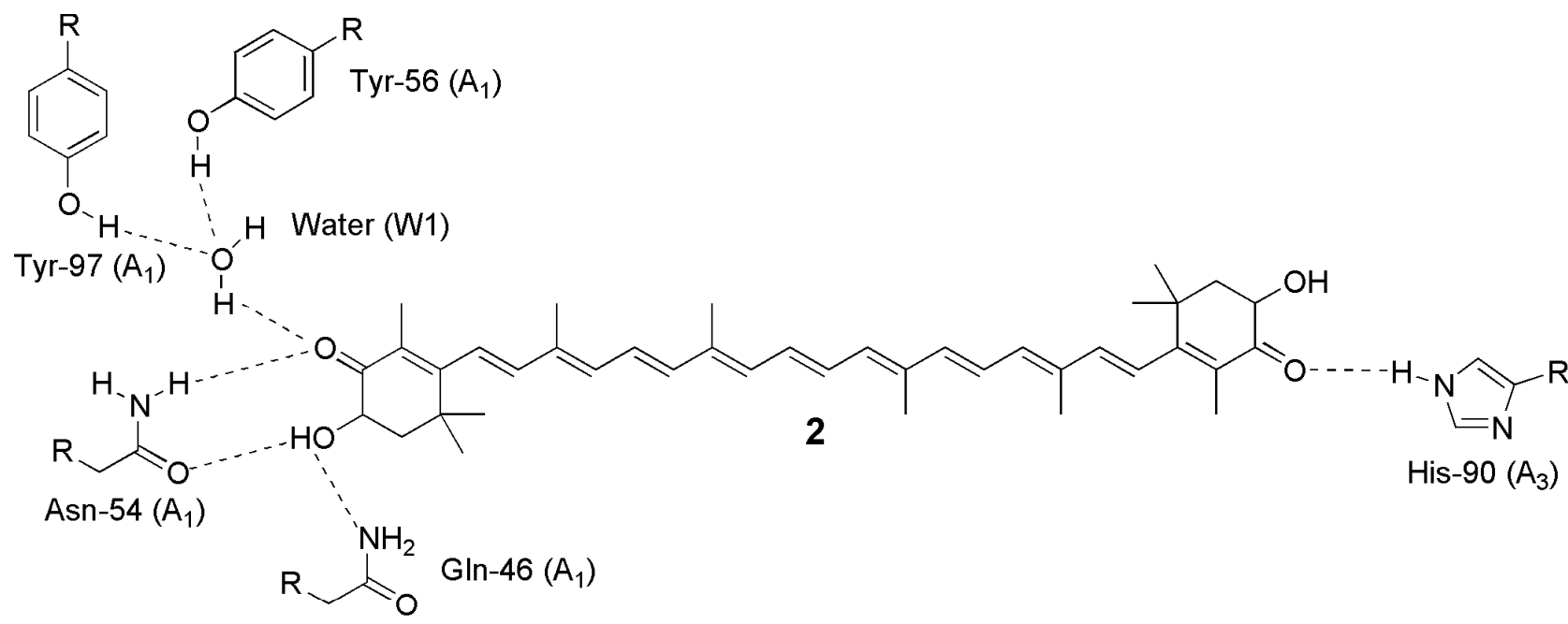

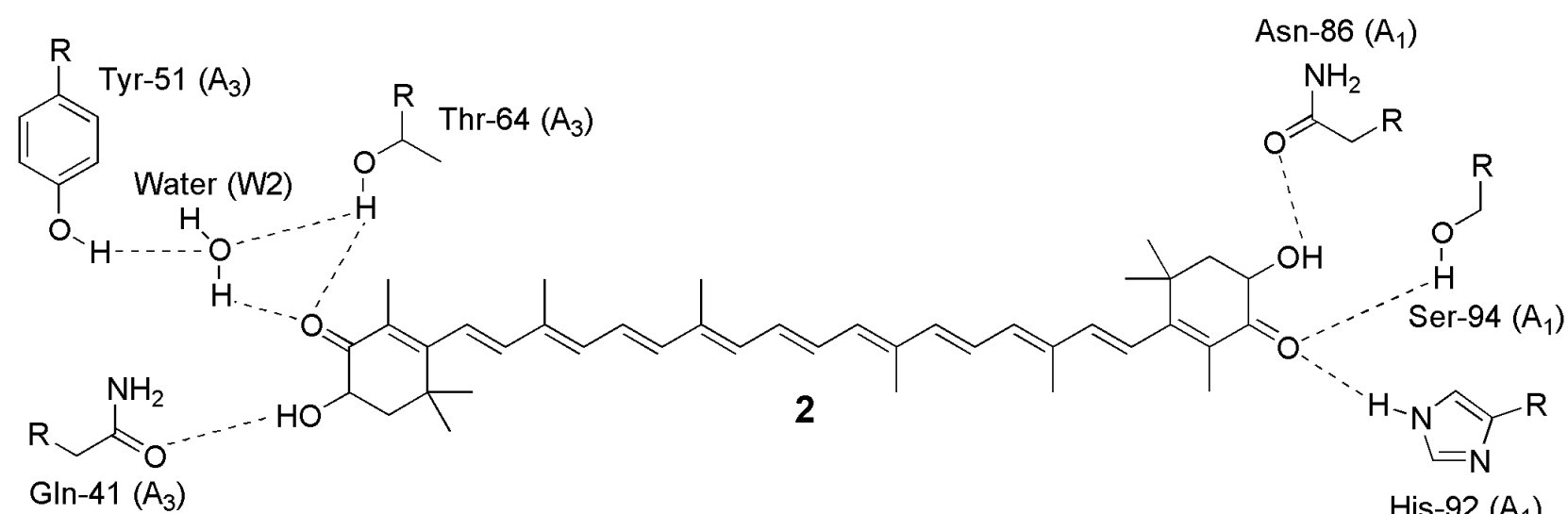

Figure 4. Astaxanthin (2) binding in $\beta$-crustacyanin. Adapted from X-ray data. ${ }^{30}$

Prior to the results of the X-ray analysis, the colouration mechanism was believed to occur by protonation of the keto-groups in astaxanthin (2), or by a polarisation. ${ }^{28,32}$ From the amino acid environment and $\mathrm{pH}$ consideration, the polarisation mechanism was not confirmed. For comparison with the ${ }^{13} \mathrm{C}$ solid state NMR shifts observed for selectively enriched astaxanthin (2) bound in recombined $\alpha$-crustacyanin, ${ }^{33}$ we have investigated by NMR the protonated products obtained by treatment of the simpler model canthaxanthin (28) by various Brønsted acids. ${ }^{34}$ The diprotonated product 29 was not achieved, but ${ }^{13} \mathrm{C}$ chemical shift data could indirectly be estimated from other 
protonated products, Figure 5. However, the ${ }^{13} \mathrm{C}$ shifts observed in the recombined $\alpha$-crustacyanin were not compatible with $\mathrm{C}=\mathrm{O}$-protonation, ${ }^{34}$ consistent with $\mathrm{X}$-ray data for $\beta$-crustacyanin. ${ }^{30}$

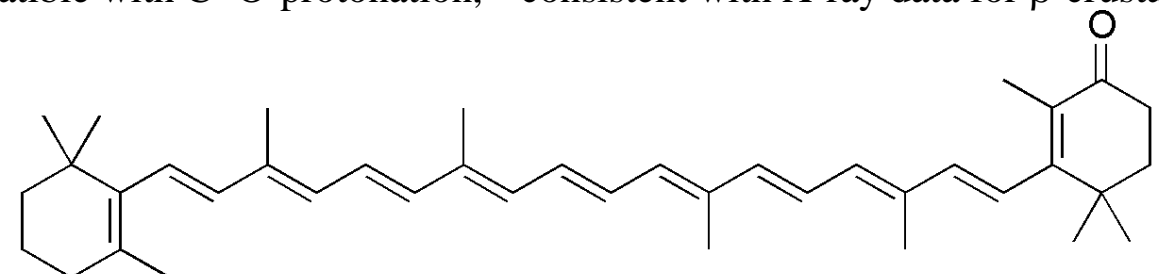

28
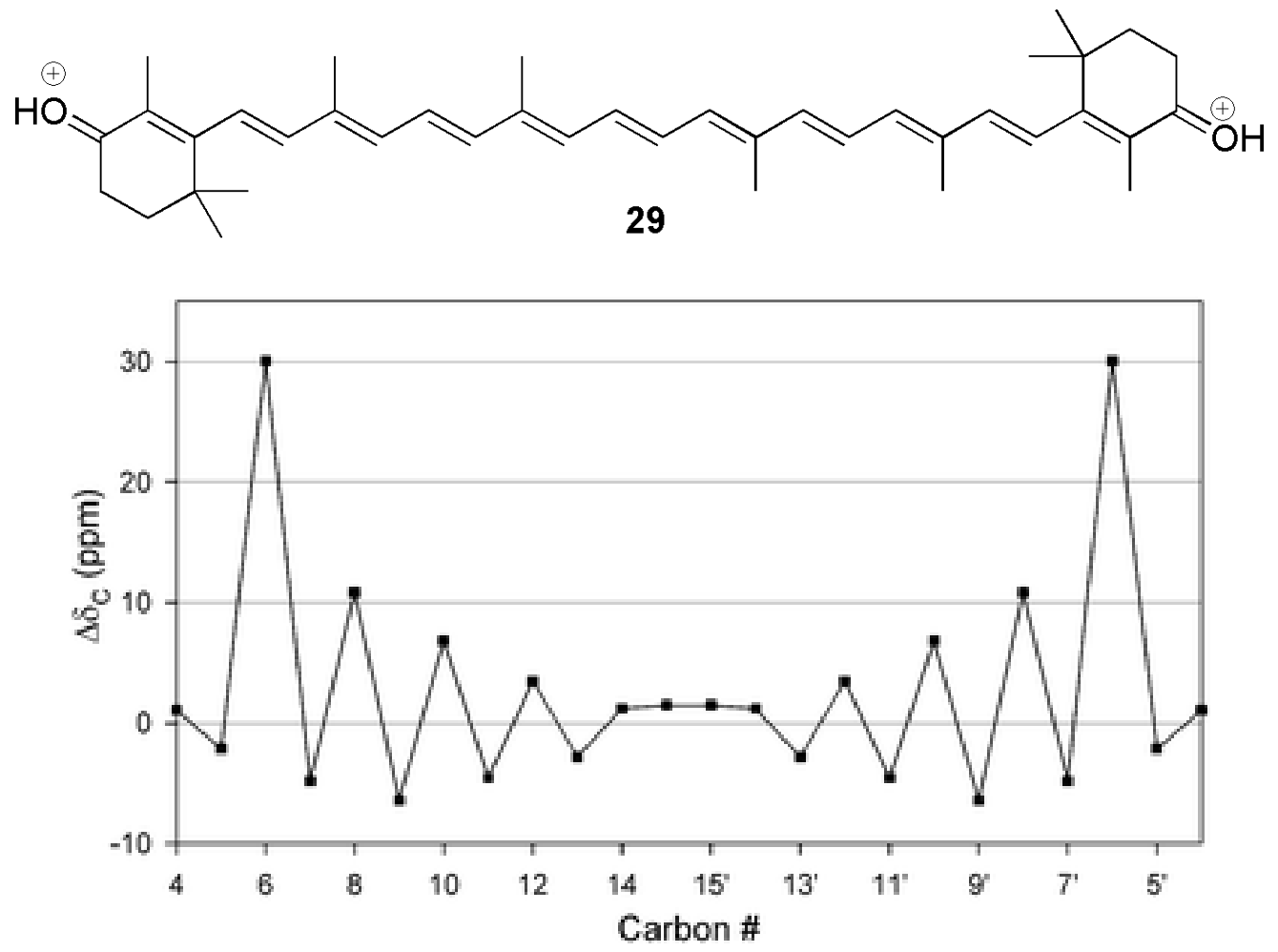

Figure 5. Expected downfield ${ }^{13} \mathrm{C}$ chemical shifts of the hypothetical O-4,4' diprotonated canthaxanthin (29) relative to canthaxanthin (28).

Based on calculations, the co-planarity of the rings with the aliphatic polyene chain should account for about a third of the bathochromic colour shift. ${ }^{33}$ However, the major contribution to the bathochromic shift of astaxanthin (2) in the absorption spectra of crustacyanins was explained by an exciton coupling effect. Bathochromic shifts are observed in exciton coupling systems if the angle between two electronic transition moments is larger than $90^{\circ} .{ }^{35,36}$ In $\beta$-crustacyanin, the two astaxanthin molecules are at a close distance, $7 \AA$, and form an exciton coupling system with an angle of $120^{\circ}$. Combined with the elongation of the conjugation of the $\pi$-system caused by coplanarity of the cyclic end group, illustrated in Figure 4, and the effect of hydrogen bonding of the keto-groups, a calculated value for $\lambda_{\max }$ in $\beta$-crustacyanin of $650 \mathrm{~nm}$ was found. ${ }^{33}$ Further proof of 
the importance of aggregation effects for the colour in lobster may be found in the additional bathochromic shift of $45 \mathrm{~nm}$ going from $\beta$-crustacyanin subunits to $\alpha$-crustacyanin. Experimental data from femtosecond time-resolved spectroscopic studies on $\alpha$-crustacyanin were found to be in agreement with dimerisation of astaxanthin (2) as the main cause of the bathochromic shift. ${ }^{37} \mathrm{X}$-ray data for another carotenoprotein, present in the cyanobacterium Arthrospira maxima, has revealed the incorporation of monomeric 3'-hydroxyechinenone (30). The smaller bathochromic shift (55 $\mathrm{nm}$ ) of $\lambda_{\max }$ observed in this carotenoprotein $\left(\lambda_{\max } 505 \mathrm{~nm}\right.$ ) is compatible with hydrogen bonding and extended $\pi$-conjugation by ring co-planarity, and with exciton effects absent. ${ }^{38}$ The blue $\left(\lambda_{\max }\right.$ $554 \mathrm{~nm}$ ) carotenoprotein asteriarubin from starfish (Asterias rubens) has a single mono- (31) or diacetylenic astaxanthin (32) molecule per protein oligomer, ${ }^{39}$ where excition interaction also may be disregarded.<smiles>CC1=C(/C=C/C(C)=C/C=C/C(C)=C/C=C/C=C(C)/C=C/C=C(C)/C=C/C2=C(C)CC(O)CC2(C)C)C(C)(C)CCC1</smiles>

30<smiles>C=C(C#C/C(C)=C/C=C/C(C)=C/C=C/C=C(C)/C=C/C=C(C)/C=C/C1=C(C)C(=O)[C@@H](O)CC1(C)C)C(C)(C)CC</smiles>

31

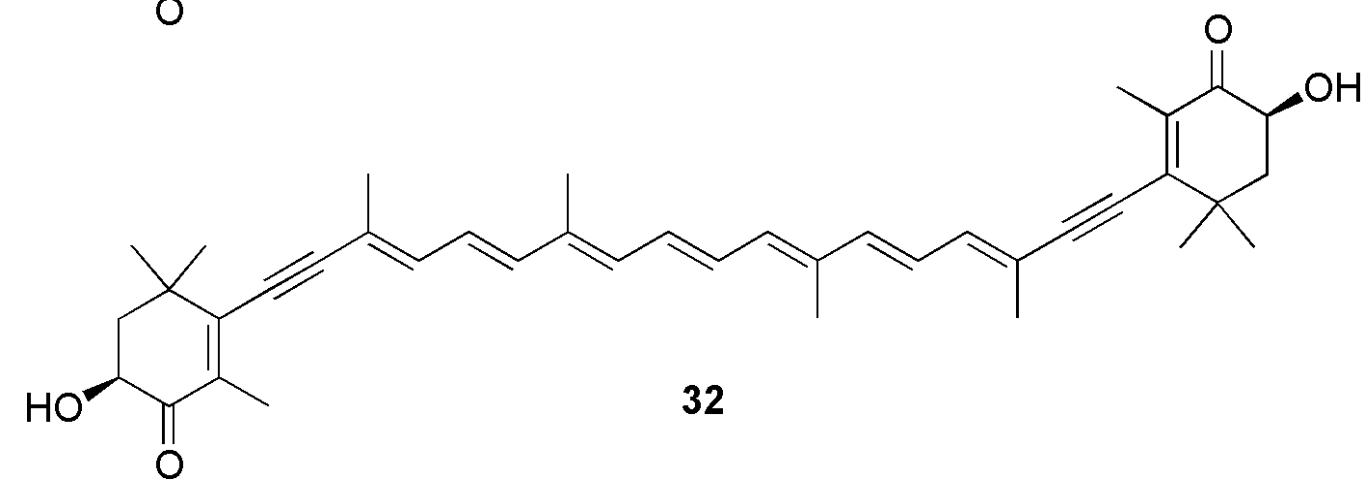

Also the blue alloporin ( $\lambda_{\max } 545 \mathrm{~nm}$ ) of coral origin contains only one astaxanthin (2) molecule per protein monomer. ${ }^{40}$ On the other hand in linckiacyanin $\left(\lambda_{\max } 612 \mathrm{~nm}\right)$ from the blue starfish Linckia laevigata, (3S,3'S)-astaxanthin ((3S,3'S)-2) is the dominant carotenoid and excition interaction between carotenoids has been suggested. ${ }^{41} \mathrm{~A}$ simple hypothesis is advanced here in Scheme 8 . 


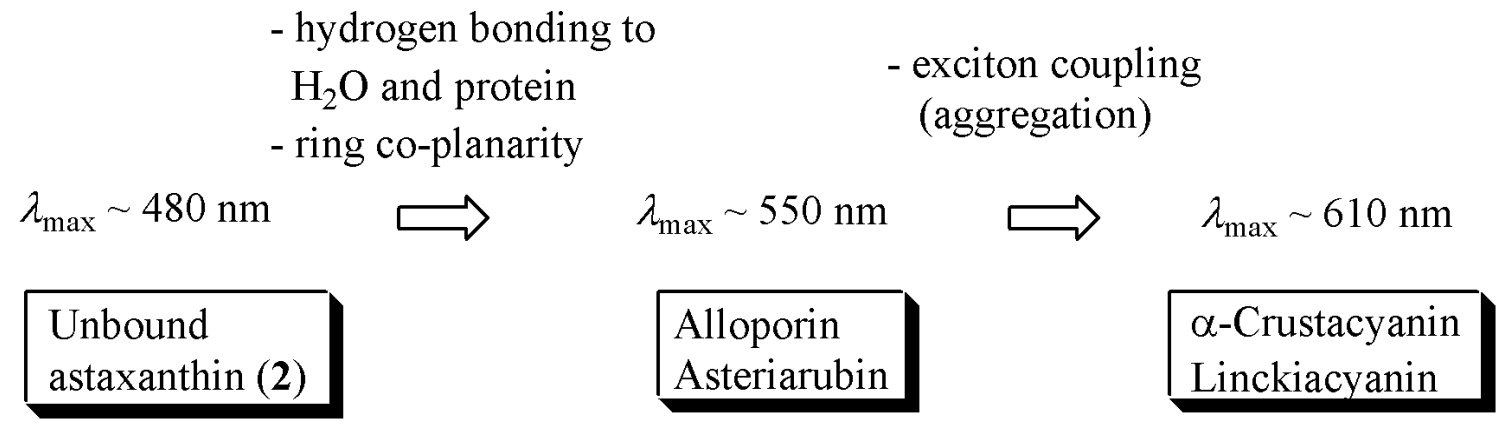

\section{Scheme 8}

As pointed out in a recent computational study, the protonation state of the histidine residues shown in Figure 4 is not known from the X-ray analysis, and protonation of astaxanthin (2) by these residues may give rise to bathochromic shifts of the same magnitude as the ones observed. Furthermore, only small bathochromic shifts (5 $\mathrm{nm}$ or less in organic solvents) was observed in a study of chiral carotenoid dimers. ${ }^{42}$ Both because of the commercial need for a stable blue colorant, and the remaining uncertainty regarding the colouration mechanism in blue carotenoproteins, efforts should be made to prepare synthetic carotenoid dimers mimicking the stereochemical relationships between the two carotenoid molecules present in $\beta$-crustacyanin.

\section{Conclusions}

The UV/VIS/NIR absorption range of carotenoids has been expanded in recent years, from yelloworange-red, Figure 3, now including colourless and blue carotenoids. Only the cyclopentenedione derivative violerythrin (5) is a blue, neutral, stable carotenoid, besides a series of blue carotenoproteins. The blue carotenoid oxonium ions, delocalized cations and radical cations (as in the iodine complex) investigated have restricted lifetimes, but offer interesting structural chemistry.

\section{References}

1. IUPAC Commission on the Nomenclature of Organic Compounds and IUB Commission on Biochemical Nomenclature Pure Appl. Chem. 1975, 41, 405.

2. Britton, G.; Liaaen-Jensen, S.; Pfander, H. Carotenoids: Handbook; Birkhäuser: Basel, 2004.

3. Widmer, E.; Lukac, T.; Bernhard, K.; Zell, R. Helv. Chim. Acta 1982, 65, 671.

4. Hertzberg, S.; Liaaen-Jensen, S.; Enzell, C. R.; Francis, G. W. Acta Chem. Scand. 1969, 23, 3290.

5. Müller, R. K.; Mayer, H.; Noack, K.; Daly, J. J.; Tauber, J. D.; Liaaen-Jensen, S. Helv. Chim. Acta 1979, 61, 2881.

6. Kienzle, F.; Minder, R. E. Helv. Chim. Acta 1976, 59, 1976. 
7. Karrer, P.; Jucker, E. Carotenoide; Birkhäuser: Basel, 1948.

8. Strain, H. H. Acta Biochem. Biophys. 1954, 48, 458.

9. Haugan, J. A.; Liaaen-Jensen, S. Acta Chem. Scand. 1994, 48, 68.

10. Haugan, J. A.; Liaaen-Jensen, S. Acta Chem. Scand. 1994, 48, 152.

11. Lutnæs, B. F. Ph.D. Thesis, Norwegian University of Science and Technology, Trondheim, 2004.

12. Kildahl-Andersen, G. Ph.D. Thesis, Norwegian University of Science and Technology, Trondheim, 2007.

13. Lutnaes, B. F.; Bruås, L.; Kildahl-Andersen, G.; Krane, J.; Liaaen-Jensen, S. Org. Biomol. Chem. 2003, 1, 4064.

14. Kildahl-Andersen, G.; Anthonsen, T.; Liaaen-Jensen, S. Org. Biomol. Chem. 2007, 5, 2803.

15. Kildahl-Andersen, G.; Bruås, L.; Lutnaes, B. F.; Liaaen-Jensen, S. Org. Biomol. Chem. 2004, 2, 2496.

16. Lutnaes, B. F.; Kildahl-Andersen, G.; Krane, J.; Liaaen-Jensen, S. J. Am. Chem. Soc. 2004, 126, 8981.

17. Kildahl-Andersen, G.; Lutnaes, B. F.; Krane, J.; Liaaen-Jensen, S. Org. Lett. 2003, 5, 2675.

18. Sorensen, T. S. In Carbonium Ions; Olah, G. A., Schleyer, P. v. R., Eds.; New York: WileyInterscience, 1970; Vol. 2, pp 807-835.

19. Jaffé, H. H.; Orchin, M. Theory and Applications of Ultraviolet Spectroscopy; John Wiley \& Sons: New York, 1962, pp 220-241.

20. Kildahl-Andersen, G.; Anthonsen, T.; Liaaen-Jensen, S. Tetrahedron Lett. 2006, 47, 4693.

21. Moore, T. Vitamin A; Elsevier: Amsterdam, 1957.

22. Rosenheim, O.; Drummond, J. C. Lancet 1920, 195, 862.

23. Rosenheim, O.; Drummond, J. C. Biochem. J. 1925, 19, 753.

24. Carr, F. H.; Price, E. A. Biochem. J. 1926, 20, 497.

25. Kildahl-Andersen, G.; Naess, S. N.; Aslaksen, P. B.; Anthonsen, T.; Liaaen-Jensen, S. Org. Biomol. Chem. 2007, 5, 3027.

26. Lutnaes, B. F.; Krane, J.; Liaaen-Jensen, S. Org. Biomol. Chem. 2004, 2, 2821.

27. Zagalsky, P. F. In Carotenoids; Britton, G., Liaaen-Jensen, S., Pfander, H., Eds.; Birkhäuser: Basel, 1995; Vol. 1A, pp 287-294.

28. Weesie, R. J.; Jansen, F. J. H. M.; Merlin, J. C.; Lugtenburg, J.; Britton, G.; de Groot, H. J. M. Biochemistry 1997, 36, 7288.

29. Renstrøm, B.; Rønneberg, H.; Borch, G.; Liaaen-Jensen, S. Comp. Biochem. Physiol. 1982, $71 B, 249$.

30. Cianci, M.; Rizkallah, P. J.; Olczak, A.; Raftery, J.; Chayen, N. E.; Zagalsky, P. F.; Helliwell, J. R. Proc. Natl. Acad. Sci. U. S. A. 2002, 99, 9795.

31. Chayen, N. E.; Cianci, M.; Grossmann, J. G.; Habash, J.; Helliwell, J. R.; Nneji, G. A.; Raftery, J.; Rizkallah, P. J.; Zagalsky, P. F. Acta Cryst. 2003, D59, 2072. 
32. Durbeej, B.; Eriksson, L. A. Phys. Chem. Chem. Phys. 2006, 8, 4053.

33. van Wijk, A. A. C.; Spaans, A.; Uzunbajakava, N.; Otto, C.; de Groot, H. J. M.; Lugtenburg, J.; Buda, F. J. Am. Chem. Soc. 2005, 127, 1438.

34. Kildahl-Andersen, G.; Lutnaes, B. F.; Liaaen-Jensen, S. Org. Biomol. Chem. 2004, 2, 489.

35. Harada, N.; Uda, H. J. Chem. Soc., Chem. Commun. 1982, 230.

36. Harada, N.; Nakanishi, K. Circular Dichroic Spectroscopy - Exciton Coupling in Organic Stereochemistry; University Science Books/Oxford University Press: Mill Valley, 1983, pp 88-91.

37. Ilagan, R. P.; Christensen, R. L.; Chapp, T. W.; Gibson, G. N.; Pascher, T.; Polívka, T.; Frank, H. A. J. Phys. Chem. A 2005, 109, 3120.

38. Kerfeld, C. A.; Sawaya, M. R.; Brahmandam, V.; Cascio, D.; Ho, K. K.; Trevithick-Sutton, C. C.; Krogmann, D. W.; Yeates, T. O. Structure 2003, 11, 55.

39. Elgsaeter, A.; Tauber, J. D.; Liaaen-Jensen, S. Biochim. Biophys. Acta 1978, B530, 402.

40. Rønneberg, H.; Borch, G.; Fox, D. L.; Liaaen-Jensen, S. Comp. Biochem. Physiol. 1979, 62B, 309.

41. Zagalsky, P. F.; Haxo, F.; Hertzberg, S.; Liaaen-Jensen, S. Comp. Biochem. Physiol. 1989, 93B, 339.

42. Köhn, S. C. J. Ph.D. Thesis, Heinrich-Heine-Universität, Düsseldorf, 2004. 